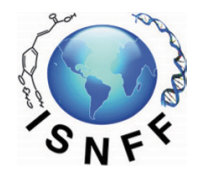

\title{
Popular functional foods and nutraceuticals with lipid lowering activity and in relation to cardiovascular disease, dyslipidemia, and related complications: an overview
}

\author{
Hui-Fang Chiu ${ }^{\mathrm{a}}$, You-Cheng Shen ${ }^{\mathrm{b}}$, Kamesh Venkatakrishnan ${ }^{\mathrm{c}}$ and Chin-Kun Wang ${ }^{\mathrm{c}}$ \\ aDepartment of Chinese Medicine, Taichung Hospital Ministry of Health and Well-being, Taichung, Taiwan \\ bSchool of Health Diet and Industry Management, Chung Shan Medical University, 110, Sec. 1, Jianguo North Road, Taichung City, \\ Taiwan \\ 'School of Nutrition, Chung Shan Medical University, 110, Sec. 1, Jianguo North Road, Taichung City, Taiwan \\ *Corresponding author: Chin-Kun Wang, School of Nutrition, Chung Shan Medical University, 110, Sec. 1, Jianguo North Road, Taichung \\ City, Taiwan. Tel: +886 4 22653397; Fax:+886 4 22654529; E-mail: wck@csmu.edu.tw \\ DOI: $10.31665 /$ JFB. 2018.2137 \\ Received: January 15, 2018; Revised received \& accepted: February 12, 2018 \\ Citation: Chiu, H.-F., Shen, Y.-C., Venkatakrishnan, K., and Wang, C.-K. (2018). Popular functional foods and nutraceuticals with lipid \\ lowering activity and in relation to cardiovascular disease, dyslipidemia, and related complications: an overview. J. Food Bioact. 2: 16-27.

\begin{abstract}
Cardiovascular disease (CVD) is the most common non-communicable ailment which claims one-third of total global death. This contribution provides an overview of cardiovascular diseases (CVDs), hypercholesterolemia and hyperlipidemia (dyslipidemia) and their related complications as well as the current treatment options with special attention to popular functional foods and nutraceuticals. Currently, many synthetic lipid-lowering drugs are available in the market. However, they trigger several adverse effects. Thus, to overcome this problem nutraceuticals and functional foods which are considered safe, and with multifaceted lipid-lowering activity are highly recommended (adjuvant therapy) for treating dyslipidemia. This review intends to shed light on how to choose the appropriate or better nutraceutical/functional food ingredients to alleviate the risk of CVD, based on recent literature survey with the inclusion of clinical trials and meta-analysis to ensure the efficacy of nutraceuticals/ functional foods on lipid profile.
\end{abstract}

Keywords: Dyslipidemia; Lipid-lowering drug; Nutraceuticals; Functional foods; Meta-analysis.

\section{Introduction}

\subsection{Cardiovascular disease (CVD)}

Cardiovascular disease (CVD) is a complicated and multifactorial ailment that mainly affects the blood vessels and subsequently the heart. CVD is not one single disease or condition which may be hereditary or acquired during the lifetime mostly due to lifestyle modifications (Dominguez et al., 2006). Five major types of CVD include ischemic heart disease (IHD), congenital heart disease (CHD) cerebrovascular disease (Stroke), rheumatic heart disease (RHD), peripheral vascular disease (PVD). CVDs is the major contributor to the total global mortality and morbidity and thus bestowed with the increased socioeconomic burden (Enas et al., 2008). CVDs account for almost $33 \%$ of all death (Chiu et al., 2016a). It has been predicted that nearly 23.6 million people will die from CVDs by the year 2030 (Jiang et al., 2011). It has been strongly believed in the past that CVD strikes mostly in old aged people, however recent studies have shown that CVDs can also strikes early and kill many people in their midlife (30-40 years). Hence CVD is considered as the world largest killer as compared to any other diseases (Pagidipati and Gaziano, 2013).

\subsection{Epidemiological studies on CVD}

Epidemiological studies play a crucial role in exploring the cor- 
relation between different predisposal factors for CVD and thus has helped in their prevention (Mahmood et al., 2014). The mortality rate of CVDs varies from place to place (geographical region) and based on different variants such as age, sex, gene, and race, among others. CVD death rates were considerably higher in Western people than Africans (Pickle and Gillum, 1999). Compared to the Western countries, the prevalence of CVD in Asians is almost four times higher. In addition, the incidence of CVD (stroke) in urban areas is much higher than rural areas in most Asian countries owing to dietary changes with a sedentary lifestyle (Ueshima et al., 2008). Several studies have indicated that adult women and men with low fitness are at the high risk of CVD (Carnethon et al., 2005; Gulati et al., 2003).

\subsection{Risk factors for CVDs}

There are some 300 risk factors associated with CVD and stroke (Mackay et al., 2004). The major ones are hypercholesterolemia (elevated levels of total cholesterol) or hyperlipidemia (elevated levels of lipids), hypertension, diabetes mellitus, male gender and postmenopausal female, obesity, smoking, family history of premature CVD, lack of exercise (sedentary lifestyle) and imbalanced food intake. Nevertheless, in the above-mentioned risk factors, hypercholesterolemia (especially low-density lipoprotein-cholesterol; LDLc) is a primary contributor to CVDs (Nordestgaard et al., 2010).

Cholesterol (waxy substance), is a crucial constituent of the plasma membrane, as well as a precursor for vitamin $\mathrm{D}$, bile acids, and sex hormones (Chen et al., 2014). Cholesterol is insoluble in blood, and hence it is carried by a special transporter called lipoproteins. Lipoproteins are packed with both proteins and lipids (Utermann, 2001). Types of lipoproteins are chylomicron (CM), very low-density lipoprotein-cholesterol (VLDL-c), LDL-c, and high-density lipoprotein-cholesterol (HDL-c) which have different lipid carrying capacities. LDL-c or bad cholesterol carries lipids from the liver to peripheral tissues. However, HDL-c or good cholesterol carries lipids from the peripheral tissues back to the liver (Chen et al., 2008).

\subsection{Hypercholesterolemia}

Hypercholesterolemia is a condition (due to metabolic derangement) where the blood cholesterol level exceeds $200 \mathrm{mg} / \mathrm{dL}$, especially LDL-c $(120 \mathrm{mg} / \mathrm{dL})$ and it is regarded as a major risk factor in the development of atherosclerosis and subsequently results in various CVD or coronary heart diseases (CHDs) (Van Rooy and Pretorius, 2014). As elevated blood cholesterol may tend to deposit in the blood vessels (plaque and fatty streak) and alter the functional properties of blood vessels which eventually results in atherosclerosis (Steinberg, 2005). Several reports have indicated that many individuals are affected by hypercholesterolemia, particularly in Western countries, due to increased sedentary lifestyle combined with diets high in saturated fat that appear to be the primary culprits in causing hypercholesterolemia, but heredity (familial hypercholesterolemia) may also be a factor for some (Pahan, 2006).

\subsection{Consequences of hypercholesterolemia}

Hypercholesterolemia is a metabolic derangement (elevated blood cholesterol level) and if it persists for a long time it would initiate different health issues. These include early-stage atherogenesis (by narrowing blood vessels due to plaque formation) through various pathological mechanism including oxidative or nitrosative stress (endothelial dysfunction), local inflammation, immunomodulation and thus results in atherosclerosis and eventually ends up in various CVDs (Lahera et al., 2007).

\subsection{Oxidative stress}

A shift in the balance between prooxidant and antioxidant (redox status) could result in oxidative stress which is associated with increased vascular/endothelial damage via excessive free radical production (Ferroni et al., 2004). Increased viscosity of blood (due to increased cholesterol concentration) might trigger vascular/endothelial injury by enhancing lipid peroxidation (via ROS) followed by accumulation and penetration of CM, VLDL-c and LDL-c into arterial or endothelial wall (polymorphonuclear leukocytes, platelets and endothelial cells). This would initiate the synthesis of various factors like plasminogen activator factor, fibroblast growth factor and cytokines (inflammatory cascade) which in turn stimulate oxidant (free radicals) producing enzymes such as NADPH oxidase (NOX), xanthine oxidase (Cardillo et al., 1997), cyclooxygenase (COX), NO synthase and lipoxygenase (Kunsch and Medford, 1999).

Therefore, the excess free radicals (ROS) can efficiently oxidize LDL-c (ox-LDL-c) and thereby increase the risk of endothelial dysfunction, atherosclerosis and subsequent CVDs (Lahera et al., 2007; Stocker and Keaney, 2004). Furthermore, superoxide $\left(\mathrm{O}_{2}{ }^{-}\right)$ rapidly reacts with $\mathrm{NO}$ to form the highly reactive intermediate peroxynitrite $\mathrm{ONOO}^{-}$. Peroxynitrite in high concentrations (nitrosative stress) is cytotoxic and may cause oxidative damage to proteins, lipids, and DNA (Cai and Harrison, 2000). Hence, oxidative/ nitrosative stress (overproduction of free radicals) during hypercholesterolemia is a major root cause for the pathophysiology of atherosclerosis and other related CVDs (Lahera et al., 2007).

\subsection{Inflammation}

Many experimental results have demonstrated that hypercholesterolemia triggers inflammation in the microvasculature, which is reflected in excessive leukocyte recruitment and platelet activation (Stokes, 2006). Activated platelet could initiate leukocyte recruitment into lesion areas by elevated CD40 expression attributing to oxidative stress (Stokes et al., 2009). Thus activated leukocytes can obstruct the capillary networks (Strokes et al., 2003) which enables the macrophages to accumulate or engulf LDL-C and oxidized LDL-C (ox-LDL-c) which develops into foam cells (Dilaveris et al., 2007). These foam cells then elicit further oxidative stress and inflammatory response via producing pro-inflammatory cytokines like interleukins one beta (IL-1 $\beta$ ), tumor necrosis factor alpha (TNF- $\alpha$ ), and interleukins 6 (IL-6), growth factors, chemokines, and acute phase proteins (Crp and fibrinogen) which aggravate the balance of endothelial equilibrium leading to endothelial dysfunction (Simionescu, 2007). Moreover, accumulation of VLDL-c and CM, in arterial wall activates the synthesis of factors protein kinase $\mathrm{C}(\mathrm{PKC})$ and nuclear factor kappa $\mathrm{B}$ (NF$\kappa \mathrm{B})$ that can initiate inflammatory responses by upregulating the expression of pro-inflammatory cytokines and cell adhesion molecules such as vascular cell adhesion molecule-1 (VCAM-1) and intercellular adhesion molecule-1 (ICAM-1) (Stemerman, 2000).

\subsection{Atherosclerosis}

Atherosclerosis is a complex multifactorial inflammatory disease, 
characterized by focal intimal thickening of medium (hardening) and large-sized arteries. These are thought to be initiated by accumulation of lipoproteins within the intima, adhesion of monocytes to the arterial endothelium, migration of monocytes into the intima, chemotactic stimuli by oxidized lipoproteins (ox-LDL-c) and accumulation of cholesterol within macrophages (Ross, 1999). The close interplay between the oxidative stress and inflammation thus provokes the vicious cycle and results in the pathogenesis of atherosclerosis (Hulsmans and Holvoet, 2010). The process of atherosclerosis can be subdivided into 4 major stages as endothelial dysfunction/lesion initiation, fatty streak, fibrous plaques, and thrombosis.

During the early stage of atherosclerosis, endothelial cells of the endothelium (blood vessel) are injured owing to excess free radical generation (oxidative/nitrosative stress), followed by local inflammatory response and chemotactic and adhesion molecule activation results in endothelial dysfunction or lesion (Steinl and Kaufmann, 2015). Subsequently, the development of foam cells (macrophage with cholesterol esters of LDL-c) starts to accumulate in the intima to form fatty streak with macrophages (ox-LDLc), T lymphocytes and adhesion molecules. This promotes the migration of leukocytes into sub-endothelial cells (chemoattractant) by degrading collagen and elastin.

The inflammatory cells are further activated to process excessive inflammatory mediators like cytokines (TNF- $\alpha$, IL-1 $\beta$, and IL6) and thereby the fatty streaks are transformed to fibrous plaque, which is capped by smooth muscle cells (SMCs) and extracellular matrix. Clinically, fibrous plaques are of two types of stable (responsible for occlusion or stenosis) and unstable (thrombosis) (Stokes et al., 2009). Finally, the intimal hyperplasia occurs with the proliferation and transmigration of smooth muscle cell of the plaques by the various inflammatory processes to worsen the process, and thus atherosclerotic plaque becomes larger and complex (due to excessive growth factors). These big complex plaques are highly prone to rupture (cause thrombosis and ischemia) and try to block both the micro or macro blood vessels. If the plaque is built up in the vessels that supply the oxygen-rich blood to the heart (coronary artery), it may cause heart attack, while its build up in the arteries that supply the oxygen-rich blood to the brain (cerebral artery) may result in stroke (Libby et al., 2009).

\subsection{Impact of hypercholesterolemia on various organs}

Hypercholesterolemia has systemic effects in various tissues. Hypercholesterolemia increases the incidence of ischemic disease in various tissues such as heart/aorta, liver, and kidney by its ability to restrict blood flow (due to lipid deposit) in lesion-prone arteries and promote ischemia (hypoxia) by enhancing vulnerability of the microcirculation and other inflammatory stimuli (Kamesh and Sumathi, 2014; 2012; Stokes et al, 2003). Intake of excessive lipids (oily stuffs) leads to severe hypercholesterolemia and vascular atherosclerotic lesion/plaque by escalating oxidative stress and inflammation (pivotal manner) and thus disrupts normal cellular function, especially cardiomyocytes, endothelium, hepatocytes and nephron and eventually ends up in hypercholesterolemic induced cardiac, endothelial, hepatic or renal dysfunction (Charradi et al., 2013; Csont et al., 2007; Deepa and Varalakshmi, 2003). As the blood cholesterol elevates it results in decreased membrane ATPases in myocytes, endothelium, and hepatocytes (Chtourou et al., 2015; Kamesh and Sumathi, 2012).

Fatty liver (accumulation of excessive fat in the liver) is the leading serious complication of chronic hypercholesterolemia or hyperlipidemia (non-alcoholic). Hypercholesterolemia (due to high intake of fatty food) causes fat deposition in the liver (fatty liver), which results in hepatic steatosis or cirrhosis of the liver and lowers the hepatocyte population via eliciting oxidative stress and inflammation. (Kamesh and Sumathi, 2012; Assy et al., 2000). Furthermore, numerous studies have indicated that hypercholesterolemia/hyperlipidemia could significantly alter renal function and play a pivotal role in the pathology of glomerulosclerosis that leads to renal ischemia (Akpolat et al., 2011; Deji et al., 2009).

Abnormal histopathological evidence like marked hypertrophy condition and focal fatty change (fat droplets) with disrupted myocardial fibers have been noted in hypercholesterolemic induced rat heart (Thiruchenduran et al., 2010; Sudhahar et al., 2007). Similarly, thickened intima and smooth muscle cell and macrophages migration with loss of elastic lamellae were observed in hypercholesterolemic induced rat aorta (Kamesh and Sumathi, 2012b; Deepa and Varlakshmi, 2005). Likewise, excessive fat accumulation (fatty liver) indicated by large lipid droplets with lipid infiltration were noted in hypercholesterolemia-induced rat liver (Kamesh and Sumathi, 2012a; Deepa and Varalakshmi, 2003). However, moderate swelling of renal tubules with the broader lumen of glomerulus were noted in hypercholesterolemia-induced rat kidney (Kamesh and Sumathi, 2014; Ying et al., 2005). These histological changes in hypercholesterolemic condition are mainly due to excessive oxidative stress and inflammatory response.

\section{Treatment approach}

An impressive number of trials have demonstrated that every $1 \%$ reduction in plasma total cholesterol would contribute to $2 \%$ reduction in the risk of CVD/CHD (Chiu et al., 2017a; Sandhya and Rajamohan, 2008). Hence, hypocholesterolemic or hypolipidemic drugs are in high demand in order to control the deleterious outcome of CVD. Monotherapy or combination therapy (adjuvant) is prescribed for treating CVD or CHD patients. Patients are requested to modify their lifestyle (regular exercise, quitting smoking or excessive alcohol consumption with balanced diet including fruits and vegetables) along with proper medication (lipid-lowering drugs; both synthetic and natural) to lower the risk rate and consequences of CVD/CHD (Sahebkar et al., 2016; Shattat, 2015).

In conformity with the National Cholesterol Education Program (NCEP) guidelines, healthcare practitioners generally prescribe cholesterol-lowering medication when LDL-c is higher than 190 $\mathrm{mg} / \mathrm{dL}$ or HDL level is less than $45 \mathrm{mg} / \mathrm{dL}$ without any known risk factors for heart disease (Pasternak, 2001). The following sections provide an account of commonly prescribed medications for hypercholesterolemia or hyperlipidemia.

\subsection{Statin drugs or HMG-CoA reductase inhibitors (atorvasta- tin, rosuvastatin, lovastatin, mevastatin, pravastatin, simvasta- tin, and fluvastatin)}

Statins (different combination) are broadly prescribed for treating hypercholesterolemia or hyperlipidemia. They are used to treat elevated LDL-c and triacylglycerol (TG) levels, as well as to improve the HDL-c levels. Healthcare practitioners prefer statin drugs owing to their active cholesterol-lowering mechanism as they inhibit endogenous cholesterol synthesis. Their adverse effects include myositis, stomach upset, rhabdomyolysis, dizziness, and hepatic damage. Some patients are intolerant to statin therapy, and hence alternative therapy is preferred (Guyton, 2010; Baigent 
et al., 2005).

\subsection{Niacin (nicotinic acid)}

Niacin is prescribed to patients with elevated LDL-c, VLDL-c, and TG levels as it is more effective in enhancing HDL-c levels than other cholesterol-lowering medications by inhibiting the hormonesensitive lipase and thus lowering the TG level and VLDL-c. However, it results in various adverse effects including stomach upset, redness or flushing of the skin, headache, dizziness, blurred vision, and liver damage. In addition, niacin usage has some limitations as it cannot be prescribed to patients with gout, diabetes, low blood pressure, or a history of peptic ulcer (Guyton and Bays, 2007).

\subsection{Bile acid sequestrants/resins (cholestyramine, colestipol, and colesevelam)}

Bile acid sequestrants are used to treat elevated LDL-c levels as they interfere with the reabsorption of bile (enterohepatic circulation) and thus utilize more cholesterol for bile production. The common adverse effects include constipation, bloating, heartburn, nausea, and elevated TG. Bile acid sequestrants are of limited use as they lead to a deficiency of fat-soluble vitamins and urinary loss of calcium (Out et al., 2012).

\subsection{Fibric acid derivatives (gemfibrozil, fenofibrate, and clofi- brate)}

Fibric acid medications are used to treat elevated TG and LDL-c as well as to improve HDL-c levels. They act as a peroxisome proliferator-activated receptor- $\alpha$ (PPAR- $\alpha$ ) agonist. Fibric acids are highly prescribed for patients who cannot tolerate niacin. Adverse effects of fibric acid derivatives include myositis, stomach upset, sun sensitivity, gallstones, irregular heartbeat, and liver damage (Davidson et al., 2007).

\subsection{Probucol and Ezetimibe (systemic)}

Probucol and Ezetimibe lower LDL-c. Probucol increases LDL-c catabolism, whereas Ezetimibe inhibits exogenous cholesterol absorption by inhibiting Niemann-Pick C1-Like 1 (NPC1L1) protein thus decreasing LDL-c levels. Both induce several adverse effects including diarrhea, bloating, gallstone, liver damage, nausea, vomiting, and dizziness (Phan et al., 2012; Yamamoto, 2008).

\subsection{PCSK9 inhibitors [Alirocumab (praluent), Evolocumab (Re- patha)]}

Proprotein convertase subtilisin kexin 9 (PCSK9) inhibitors (monoclonal antibody as injectable form) are included as major lipid lowering drugs (recently) as they improve the LDL receptor count, and thus the levels of LDL-c can be significantly lowered (Tibolla et al., 2011). They can also be prescribed with statins, but they exhibit few adverse effects including nasopharyngitis, myositis, musculoskeletal pain, diarrhea, cough, flu, and constipation. The major limitation of such drugs is the cost (expensive), administration route (only injectable form) and they also produce immunoresistance in some patients (Chaudhary et al., 2017; Katsiki et al., 2017).

Few other minor lipid or cholesterol-lowering drugs including
acyl-CoA cholesterol acyl transferase (ACAT) inhibitor, microsomal triacylglycerol transfer protein (MTTP) inhibitor, cholesteryl ester transfer protein (CETP) inhibitor, squalene synthase inhibitors and ATP citrate lyase inhibitor may also be prescribed to CVD or CHD patients with standard lipid-lowering drugs for better results (Shattat, 2015).

\subsection{Alternative or complementary therapy}

The above-mentioned lipid-lowering synthetic drug have many adverse effects. In view of this, the quest for natural products (functional foods/nutraceuticals) with lipid-lowering potential and with minimal or no side effects is warranted. In recent years, the use of medicinal plants/herbs/food components (alternative or complementary therapy) in medicine, most importantly, in the treatment of dyslipidemia and related CVDs has witnessed a surge of interest because of relative cost-effectiveness, being well tolerated, safe and due to the absence or less adverse effects (Chen et al., 2014; Nies et al., 2006; Fogari and Zoppi, 2004). Moreover, the European guidelines of management of dyslipidaemias (EGMD) and NCEP have recommended the use of nutraceuticals or functional foods as an adjuvant therapy with standard lipid-lowering drugs (Catapano et al., 2011; Expert Panel of NCEP, 2001).

\subsection{Major nutraceuticals/functional foods with lipid-lowering activity}

To date, no studies have shown that an alternative therapy alone could effectively lower the cholesterol or lipid levels when compared to other standard lipid-lowering drugs such as statins (Nelson, 2013). Nevertheless, few nutraceuticals/functional foods are reported to show mild to moderate lipid-lowering activity. Therefore, few major popular nutraceutical/functional food ingredients with hypocholesterolemic or hypolipidemic activities such as plant sterols/stanols, red yeast rice, green tea catechins (eg., epigallocatechin gallate; EGCG), curcumin, berberine, garlic, spirulina, fish oil (omega-3-fatty acids- docosahexaenoic acid; DHA and eicosapentaenoic acid; EPA), soybean (protein), pre- and probiotics and soluble fibers as well as other minor lipid lowering nutraceuticals/ functional foods like grape seed polyphenol (resveratrol), quercetin (onion), royal jelly (honey), and prune are discussed briefly with respect to mechanism and meta-analysis (Randomized Clinical Trials; RCTs). Table 1 represents the various major functional foods and nutraceuticals with their specific lipid lowering properties.

\subsection{Plant sterols and stanols}

Plant sterols (sitosterol and campesterol) and stanols (sitostanol and campestanol) are the natural components of plant cell membrane, which structurally resemble cholesterol (agonist) and thus lower the cholesterol level (Mannarino et al., 2009; Nguyen et al., 1999). Epidemiological studies have inferred that intake of dietary plant sterols (at a dose of $2 \mathrm{~g} /$ day) is inversely proportionate to total cholesterol and LDL-c (Klingberg et al., 2008; Andersson et al., 2004). Phytosterols/stanols are reported to interfere in micelle formation (lower the exogenous cholesterol absorption) and effectively inhibit the bile acid reabsorption thus indirectly diminish the cholesterol pool (Gylling et al., 2013; Musa-Veloso et al., 2011). Furthermore, a meta-analysis including 41 RCTs provided with phytosterols (mayonnaise, yogurt, bread, and milk) for an average of 28 days 
Table 1. represent the various major functional foods and nutraceuticals with their specific lipid lowering properties

\begin{tabular}{|c|c|}
\hline Functional Foods and Nutraceuticals & Lipid lowering (cardioprotective) property \\
\hline $\begin{array}{l}\text { Plant sterols (sitosterol \& campesterol) and stanols } \\
\text { (sitostanol \& campestanol) }\end{array}$ & $\begin{array}{l}\text { Interfere in micelle formation, inhibit the bile acid reabsorption (diminish the } \\
\text { cholesterol pool) }\end{array}$ \\
\hline Red Yeast Rice (monacolins) & HMG Co-A reductase inhibitor \\
\hline Green tea catechins (EGCG) & $\begin{array}{l}\text { HMG Co-A reductase inhibitor, interferes with micelle formation, upregulate the } \\
\text { expression of hepatic LDL-R, increase the biliary excretion }\end{array}$ \\
\hline Turmeric (Curcumin) & Inhibiting NPC1L1 transporter expression, upregulate hepatic LDL-R production \\
\hline Berberine & $\begin{array}{l}\text { Natural PCSK-9 inhibitor, upregulate the expression of hepatic LDL-R, interferes } \\
\text { with micelle formation }\end{array}$ \\
\hline Garlic (S-allylcysteine) & HMG Co-A reductase inhibitor, inhibit the activity of ACAT and gastric lipase \\
\hline Spirulina (C-phycocyanin) & Interfere in bile acid reabsorption, enhance hepatic lipase activity \\
\hline Fish oil (DHA and EPA) & $\begin{array}{l}\text { Increasing the expression of LPL and fatty acid oxidation enzymes, downregulate } \\
\text { the expression of VLDL receptor }\end{array}$ \\
\hline Soybean (protein/peptide and (isoflavones-equol) & Increase bile acid excretion, downregulate SREBP protein expression \\
\hline Pre- and probiotics (SCFA) & $\begin{array}{l}\text { Upregulate the BSH enzyme (decrease bile acid reabsorption), modulate } \\
\text { cholesterol synthesis (HMG Co-A reductase inhibitor) }\end{array}$ \\
\hline Soluble fibers (oat, barley- $\beta$-glucan) & $\begin{array}{l}\text { Act as bile acid sequestrants, inhibit fatty acid synthesis and upregulate the } \\
\text { expression of hepatic LDL-R }\end{array}$ \\
\hline
\end{tabular}

showed a significant reduction in LDL-c levels (Demonty et al., 2008). Another meta-analysis, carried out by Ras et al. (2014), indicated a significant reduction of LDL-c (6 to $12 \%$ ) at a dose of less than $3 \mathrm{~g} /$ day. Furthermore, phytosterol is reported to lower the total cholesterol, LDL-c, and TG along with 8-isoprostane levels in hypercholesterolemic patients (Mannarino et al., 2009).

\subsection{Red yeast rice (RYR)}

RYR has been used in traditional Chinese medicine (TCM) for many years to aid digestion and blood circulation (Ma et al., 2000). It a fermented product (yeast on rice) rich in monacolins that displays a broad range of biological activities and thus recommended as a functional food (Verhoeven et al., 2013). Previously, few studies have shown that it may cause several adverse effects and hence FDA did not permit its marketing in the US (Gordon et al., 2010). However, it has been marketed in Asia and Africa. It is a potent HMG Co-A reductase inhibitor (monocolins $\mathrm{K}$ has structural similarity with statins) and hence used for patients with statin intolerance (Burke, 2015). Gerards et al. (2015), in their systemic review and meta-analysis, indicated that red yeast rice extract could significantly lower the LDL-c level, with acceptable adverse events and thus recommended it for treating dyslipidemia. Italian hypercholesterolemic patience supplemented with red yeast rice (rich in monacolins) for 4 weeks experienced a significant decrease in the levels of total cholesterol (12.5\%) and LDL-c (22\%), but no changes were noted in TG or HDL-c levels. Another clinical trial also confirmed the hypolipidemic or hypocholesterolemic activity of red yeast rice by reducing the plasma TC, LDL-c, and TG in statin-intolerant hypercholesterolemic subjects (Chung et al., 2014).

\subsection{Green tea catechins (mainly EGCG)}

Green tea is prepared from the plant Camellia sinensis, which is consumed globally and is known to have various health benefits
(Gaur and Agnihotri, 2014). Catechins are the major components of green tea with various pharmaceutical activities. In particular, epigallocatechin-3-gallate (EGCG) plays a crucial role in many beneficial properties (Chiu et al., 2016b; Koo et al., 2007). Green tea is a potent $\mathrm{HMG} \mathrm{Co-A} \mathrm{reductase} \mathrm{inhibitor,} \mathrm{it} \mathrm{also} \mathrm{interferes} \mathrm{with}$ micelle formation and thereby lowers the cholesterol level. Moreover, EGCG is reported to enhance the expression of hepatic LDLReceptor (LDL-R) and increases the biliary excretion and which in turn reduces the cholesterol level (Koo et al., 2007; Shishikura et al., 2006). A systemic review and meta-analysis conducted by Kim et al. (2011) indicates that green tea catechins (GTCs) can significantly lower the TC and LDL-c levels and thus contribute to the hypocholesterolemic activity. However, no significant changes were observed in the levels of TG or HDL-c. Another study confirmed that consumption of theoflavin enriched green tea extract could significantly lower the TC and LDL-c levels in hypercholesterolemic subjects (Maron et al., 2003).

\subsection{Turmeric (curcumin)}

Curcumin is one of the major active components (polyphenolic) of turmeric (Curcuma longa). It has been extensively used for cooking as well as for treating various ailments and thus considered as a popular neutraceutical/functional food ingredient (Zlotogorski et al., 2013). Curcumin can exhibit its hypolipidemic or hypocholesterolemic property by inhibiting NPC1L1 transporter expression (Kumar et al., 2011), also by upregulating LDL-R production via downregulating PCSK-9 (Tai et al., 2014). The clinical trial conducted by Yang et al. (2014) revealed that 12 weeks of supplementation with curcumin extract significantly lowered the level of LDL-c whereas the level of HDL-c was considerably improved in patients with metabolic syndrome. Moreover, another trial also confirmed the hypolipidemic or hypocholesterolemic activity; during this trial subjects were asked to consume curcumin for 8 weeks which resulted in a significant reduction in the levels of TC, LDL-c and TG as compared with the control group (Panahi et al., 2016). 


\subsection{Berberine}

Berberine is an alkaloid which occurs in plants of coptis, as well as berries family, including barberry (Berberis vulgaris), and tree turmeric (Berberis aristata) (Gupta et al., 2014). Many studies have demonstrated the lipid-lowering property of berberine and hence it is considered as a major nutraceutical for treating dyslipidemia (Derosa et al., 2012; Marazzi et al., 2011). It acts as a potent natural inhibitor for PCSK-9 and thus improves the number of hepatic LDL-R. In addition, it directly upregulates the production of LDL-R and thereby lowers the cholesterol levels (Li et al., 2009; Lee et al., 2007). Moreover, it might decrease intestinal cholesterol absorption by interfering with micelle formation (increase the cholesterol and bile acid excretion), and thereby improves hepatic cholesterol turnover (Li et al., 2015; Kong et al., 2004). A meta-analysis conducted by Dong et al. (2013), with 11 RCTs concluded that consumption of berberine (mean dose of 500-1,000 $\mathrm{mg} /$ day) in hypercholesterolemic patients would exert a positive effect by considerably lowering the levels of TC, LDL-c, and TG with increased HDL-c. In addition, supplementation of berberine pill (alone) in hypercholesterolemic patients resulted in 32, 24 and $19.5 \%$ reduction in the levels of LDL-c, TC and TG, respectively, than ezetimibe (Pisciotta et al., 2012). Berberine is commonly combined with red yeast rice and policosanols for treating dyslipidemia (Marazzi et al., 2011; Affuso et al., 2010).

\subsection{Garlic}

Garlic (Allium sativum) is well known for its wide spectrum of beneficial properties (mainly due to sulfur-containing compounds, namely allicin/S-acetylcysteine) and hence is considered as a functional food (Gupta et al., 2015). Many studies have concluded that S-allylcysteine is the major contributor to the lipid-lowering or anti-atherogenic activity of garlic (Jung et al., 2014; Kwak et al., 2014). The mechanism behind the hypocholesterolemic activity of garlic and its S-allylcysteine is the inhibition of HMG- CoA reductase (Mathew et al., 2004). It might also inhibit the activity of ACAT and gastric lipase, and thus the levels of blood cholesterol were significantly reduced (Zeng et al., 2012; Khatua et al., 2013). A meta-analysis conducted by Ried et al. (2013), with 39 primary trials, demonstrated that administration of garlic for 2 months could effectively reduce the levels of total cholesterol, low-density lipoprotein cholesterol in hypercholesterolemic subjects. However, no significant changes were noted in the levels of TG or HDLc. In addition, supplementation of aged black garlic for 12 weeks substantially improved the HDL-c level without altering TC or LDL-c in hypercholesterolemic subjects (Jung et al., 2014).

\subsection{Spirulina}

Spirulina is a free-floating filamentous microalga that has been used as a highly nutritive supplement (especially for protein and vitamins) for many years, and hence it has been approved by FDA (Mazokopakis et al., 2014). The lipid-lowering activity of spirulina may interfere with bile acid reabsorption (increase fecal bile acid) and thus improve hepatic cholesterol turnover, increase hepatic lipase activity and thereby lower the cholesterol level (Deng and Chow, 2010). Since spirulina is rich in various nutrients, it is hard to predict the active components responsible for its lipid-lowering activity. However, Nagaoka et al. (2005) reported that C-phycocyanin (chromoprotein) might be the contributor to hypolipidemic activity. Few RCTs studies conducted on hypercholesterolemic subjects supplemented with spirulina demonstrated reduced lipid profile (TC, TG, and LDL-c), but no change in HDL-c levels were noted (Kim and Kim, 2005; Ramamoorthy and Premakumari, 1996). To evaluate the hypolipidemic effect of spirulina, a metaanalysis was conducted with seven RCTs, in dyslipidemic subjects which showed that those supplemented with spirulina had a significant reduction in TC $(47 \mathrm{mg} / \mathrm{dL})$, LDL-c $(41.32 \mathrm{mg} / \mathrm{dL})$ and TG $(44.23 \mathrm{mg} / \mathrm{dL})$ with elevation in the levels of HDL-c $(6.06 \mathrm{mg} /$ dL) (Serban et al., 2016).

\subsection{Fish oil (omega-3-fatty acids- DHA and EPA)}

Fish oil is rich in omega-3-fatty acids such as docosahexaenoic acid (DHA) and eicosapentaenoic acid (EPA) renders numerous biological functions (Shahidi and Ambigaipalan, 2018; Hooper et al., 2006). It has been proposed that omega-3-fatty acids can lower the TG by increasing the expression of lipoprotein lipase (LPL) enzyme and fatty acid oxidation, as well as downregulating the expression of VLDL receptor and thereby indirectly lowering the levels of TC and partially LDL-c (Adkins and Kelley, 2010). To check the magnitude of fish oil in hyperlipidemia, a meta-analysis was performed which included 47 studies ( $3.25 \mathrm{~g}$ of EPA or DHA), shows clinically significant reduction of TG with a mild increase in HDL-c levels, but no change in LDL-c or TC levels was noted (Eslick et al., 2009). Another, meta-analysis conducted by Zhu et al. (2014), including 13 RCTs in dialysis patients, demonstrated that serum TC $(4.63 \mathrm{mg} / \mathrm{dL})$ and TG $(20.35 \mathrm{mg} / \mathrm{dL})$ were significantly declined and a substantial improvement in the levels of HDL-c $(7.72 \mathrm{mg} / \mathrm{dL})$ was noted in fish oil group as compared with the control group. Recently, a clinical trial also showed similar results, with a significant decline in the levels of TG with improved HDL-c levels after consumption of fish oil for 3 months in type 2 diabetic patients with obesity (Wang et al., 2017).

\subsection{Soybean protein/peptide}

Several studies have indicated that soybean (soy protein/peptide) consumption could positively regulate the lipid profile or metabolism owing to the presence of bioactive peptides (hydrolysate) and isoflavones-equol (Cicero et al., 2017; Weggemans and Trautwein, 2003). The exact mechanism behind the hypolipidemic or hypocholesterolemic activity of soybean is still unclear. Nevertheless, few hypotheses have been proposed including excessive excretion of bile acid in feces, inhibition of endogenous cholesterol synthesis and marked downregulation of SREBP protein expression (Cho et al., 2007; Rebholz et al., 2013). Later, Tokede et al. (2015) carried out a meta-analysis with $35 \mathrm{RCTs}$ and concluded that intake of soy products (rich in proteins) at a dose of 3-6 g/day exhibit a potent hypocholesterolemic activity by concomitantly lowering the levels of total cholesterol, LDL-c, and TG with improved HDL-c levels. In the past, Hoie et al. (2005) demonstrated that 8 weeks of supplementation with soy protein (two different types) considerably lowered the total cholesterol, LDL-c, and apolipoprotein B levels without altering the levels of HDL-c or TG.

\subsection{Pre- and probiotics (fermented plant extract/fermented dairy products)}

Probiotics are living micro-organism which constitute the gut microbiota. However, prebiotics (nutraceuticals, functional food ingredients, especially dairy or fermented products) promote pro- 


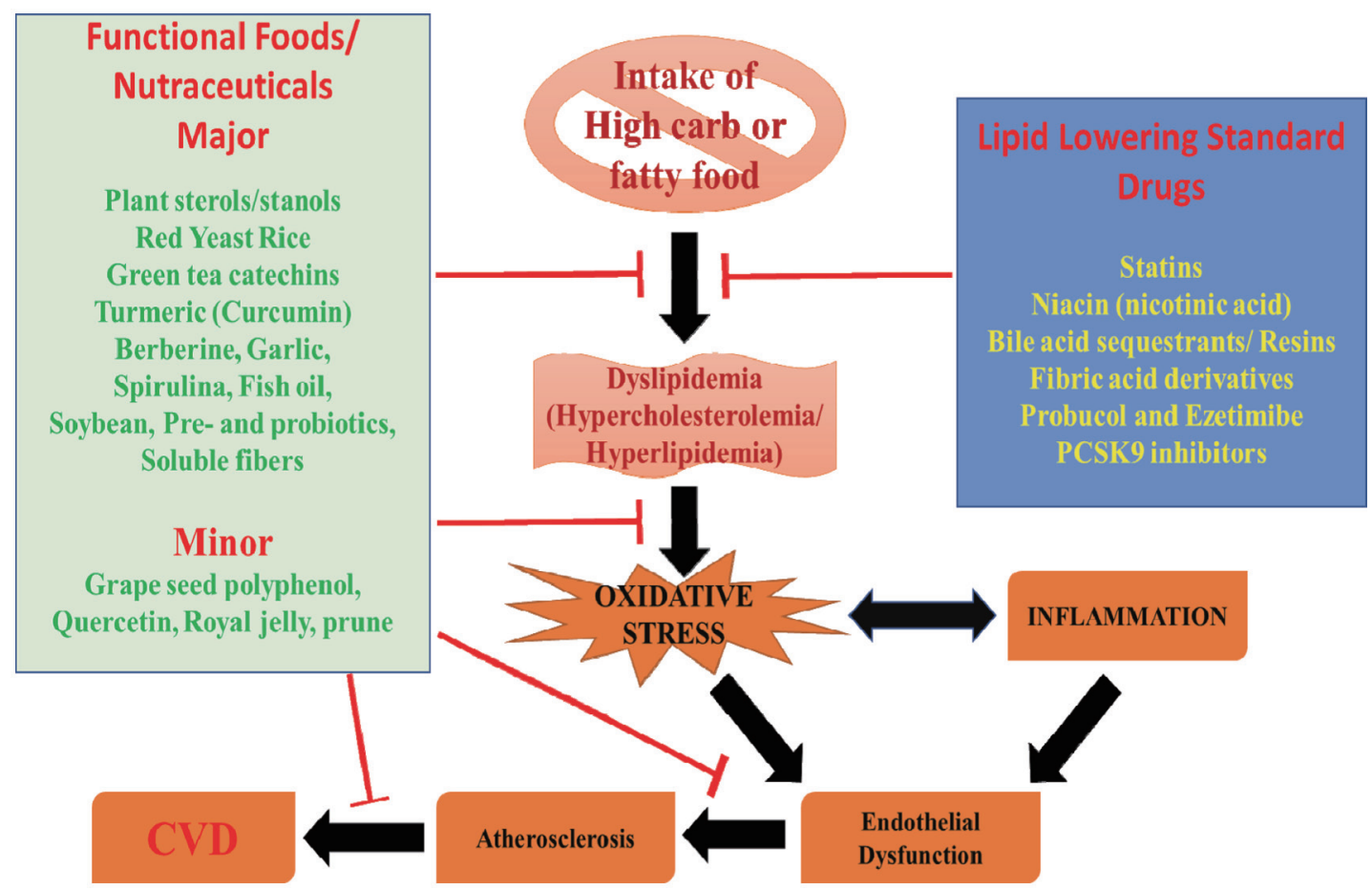

Figure 1. Schematic representation of mechanism of action of functional foods and nutraceuticals.

biotics and result in healthy gut microbiota. Hence, many researchers these days focus on the beneficial properties of gut microbiota (using various prebiotics) on CVDs, as they play a central role in host lipid metabolism (Thushara et al., 2016; Ryan et al., 2015). Few probiotics (Lactobacillus and Bifidobacterium) are directly involved in hypocholesterolemic or hypolipidemic activity by upregulating the bile salt hydrolase (BSH) enzyme which in turn increase the formation of deconjugated bile acids and thus decrease the bile acid reabsorption in the ileum (Jones et al., 2013). In addition, probiotics can improve the short chain fatty acid (SCFA) metabolism and thus modulate the lipid metabolism by altering the secretion of cholesterol and hormones (Ryan et al., 2015). A metaanalysis of 13 RCTs evaluated the effect of probiotics on lipid profile. The data revealed a significant decrease in the mean value of TC $(6.40 \mathrm{mg} / \mathrm{dL})$, LDL-c $(4.90 \mathrm{mg} / \mathrm{dL})$, and TG $(3.95 \mathrm{mg} / \mathrm{dL})$ in a probiotic-treated group than the control group (Guo et al., 2011). Several clinical trials have also confirmed the hypocholesterolemic effects of probiotics (Lactobacillus reuteri) when delivered in yogurt or capsule in healthy hypercholesterolemic subjects (Rerksuppaphol and Rerksuppaphol, 2015; Fuentes et al., 2013; Jones et al., 2012). Furthermore, Chiu et al. (2016c) demonstrated that drinking fermented plant extracts (prebiotic) would significantly improve gut microbiota (improve probiotics) and thereby considerably lower the TC, LDL-c in mildly hypercholesterolemic subjects.

\subsection{Soluble fibers (oat, barley- b-glucan)}

Overwhelming evidence indicates that soluble fibers render better lipid lowering property than their insoluble counterparts (Chen et al., 2008; Erkkila and Lichtenstein, 2006). Soluble fibers like those of oats and barley rich in $\beta$-glucan might contribute to their lipidlowering property by acting as bile acid sequestrants and inhibit fatty acid synthesis as well as by upregulating LDL-R and thus lowering TC, LDL-c and TG levels (Mannarino et al., 2014). In addition, it reduces insulin secretion and therefore decreases glucose absorption, which in turn attenuates cholesterol synthesis in the liver (Mann et al., 2007). A meta-analysis conducted by Brown et al. (1999) with 67 RCTs investigated the lipid-lowering effect of soluble fibers (dose of 2 to $10 \mathrm{~g} /$ day) and revealed a reduction of TG by $1.25 \mathrm{mg} / \mathrm{dL}$, LDL-c by $2.2 \mathrm{mg} / \mathrm{dL}$ for every $1 \mathrm{~g}$ of soluble fibers. Another meta-analysis with $28 \mathrm{RCTs}(>3 \mathrm{~g}$ of $\beta$-glucan) also indicated that consumption of oat ( $\beta$-glucan) could significantly reduce the levels of TC and LCD-c without any change in HDL-c as compared to the baseline (Whitehead et al., 2014).

Other minor hypolipidemic or hypocholesterolemic agents including resveratrol (red wine), quercetin (onion juice), royal jelly (honey), prune juice, anthocyanins, play a crucial role in reducing the CVD risk, that was evidenced by few preclinical and clinical studies.

\subsection{Grape polyphenols (red wine)}

Grape/wine polyphenols is the major reason for the French paradox (Chen et al., 2008). Numerous studies have confirmed that the cardioprotective activity of grapeseed polyphenol extract is due to the presence of proanthocyanidins and resveratrol (Chiu et al., 2016b; Berrougui et al., 2009; Bagchi et al., 2003). A clinical trial conducted by Razavi et al. (2013) concluded that supplementation of grapeseed extract for 8 weeks significantly lowered the total cholesterol (by $10.68 \mathrm{mg} / \mathrm{dL}$ ), LDL-c (by $9.66 \mathrm{mg} / \mathrm{dL}$ ), but a slight decrease in the levels of VLDL and TG.

\subsection{Quercetin (onion)}

There is ample evidence confirming lipid-lowering activity of on- 
ion attributed mainly to its high content of flavonoids, especially quercetin (Gnoni et al., 2009; Glasser et al., 2002). The proposed lipid-lowering activity mechanism of quercetin increased fecal bile acid excretion and cholesterol absorption as well as upregulation of LDL-R protein expression, thus it efficiently reduced the blood lipid levels (Lee et al., 2011; Arai et al., 2000). A clinical trial conducted by $\mathrm{Lu}$ et al. (2015) also confirmed that consumption of quercetin-rich onion juice for 8 weeks considerably attenuated the total cholesterol, and LDL-c in mildly hypercholesterolemic subjects.

\subsection{Royal jelly (honey)}

Royal jelly (RJ) is a secretory product from the worker's bees, and it is rich in lipids, protein, carbohydrates, vitamins and minerals, therefore it is recommended as a functional food due to its high nutritive value (Ramadan and Al-Ghamdi, 2012; Isidorova et al., 2009). Many studies have indicated that major RJ proteins (MRJP) might interfere in micelle formation, upregulate protein expression of cholesterol-7 $\alpha$ hydrolase (CYP7A1) enzyme, which is involved in bile acid synthesis and thus lowering lipid levels (Nagaoko et al., 2010; Kashima et al., 2014). The above statement was well supported by a recent clinical trial conducted by Chiu et al. (2017a) who confirmed that the intake of RJ for 3 months markedly improved lipid profile and thereby showcasing its hypolipidemic property in mildly hypercholesterolemic adults.

\subsection{Prune juice}

Prune (Prunus domestica) has been extensively used for its various biological properties and hence considered as a functional food (Sapuntzakis et al., 2001). Few pre-clinical studies have demonsrated the lipid-lowering activity of prune due to the presence of pectin, and phytosterols by enhancing bile acid excretion and by hindering bile cholesterol absorption as well as by upregulating the expression of hepatic LDL-R (Igwe and Charlton, 2016; Sapuntzakis, 2013). Lately, a clinical trial by Chiu et al. (2017b) highlighted that consumption of prune juice lowers the total cholesterol by $7 \%$, and LDL-c by $6.5 \%$ in mild hypercholesterolemic individuals.

Limitation of the present review are only focusing on the popular (major/minor) nutraceuticals/functional foods with hypocholesterolemic or hypolipidemic activities and their mechanism. Nevertheless, few more nutraceuticals/functional foods (non-popular) are also focused for hypocholesterolemic or hypolipidemic activities. The schematic representation of present review is portraited in Figure 1.

\section{Conclusion}

The current recommendations for treating hypercholesterolemia/ hyperlipidemia, especially with major (popular) and minor nutraceuticals/functional foods (lipid-lowering property) including meta-analysis and RCTs. Based on the evidences provided, we recommend that nutraceuticals/functional foods (plant sterols/ stanols, red yeast rice, green tea catechins, curcumin, berberine, garlic, spirulina, fish oil, soybean (protein), pre- and probiotics and soluble fibers) might be used in monotherapy or combination therapy (adjuvant therapy) with other standard lipid-lowering drugs to combat the CVD-related complications. However, further studies are required to determine the dosage of these nutraceuticals/functional foods and to identify fully the active components responsi- ble for their lipid-lowering activity.

\section{Conflict of interest}

Author declare no conflict of interest to disclose.

\section{References}

Adkins, Y., and Kelley, D.S. (2010). Mechanisms underlying the cardioprotective effects of omega-3 polyunsaturated fatty acids. J Nutr. Biochem. 21(9): 781-792.

Affuso, F., Ruvolo, A., Micillo, F., Saccà, L., and Fazio, S. (2010). Effects of a nutraceutical combination (berberine, red yeast rice and policosanols) on lipid levels and endothelial function randomized, doubleblind, placebo-controlled study. Nutr. Metab. Cardiovasc. Dis. 20(9): 656-661.

Akpolat, M., Kanter, M., Topcu-Tarladacalisir, Y., and Aydogdu, N. (2011). Protective effect of flaxseed oil on renal injury in hyperlipidaemic rats: The effect of flaxseed oil on hyperlipidaemia. Phytother. Res. 25(6): 796-802.

Andersson, S.W., Skinner, J., Ellegård, L., Welch, A.A., Bingham, S., Mulligan, A., Andersson, H., and Shaw, K.T. (2004). Intake of dietary plant sterols is inversely related to serum cholesterol concentration in men and women in the EPIC Norfolk population: a cross-sectional study. Eur. J. Clin. Nutr. 58(10): 1378-1385.

Arai, Y., Watanabe, S., Kimira, M., Shimoi, K., Mochizuki, R., and Kinae, N. (2000). Dietary intakes of flavonols, flavones and isoflavones by Japanese women and the inverse correlation between quercetin intake and plasma LDL cholesterol concentration. J. Nutr. 130(9): 2243-2250.

Assy, N., Kaita, K., Mymin, D., Levy, C., Rosser, B., and Minuk, G. (2000). Fatty infiltration of liver in hyperlipidemic patients. Dig. Dis. Sci. 45(10) 1929-1934.

Bagchi, D., Sen, C.K., Ray, S.D., Das, D.K., Bagchi, M., Preuss, H.G., and Vinson, J.A. (2003). Molecular mechanisms of cardioprotection by a novel grape seed proanthocyanidin extract. Mutat. Res./Fund. Mol. Mech. M. 523: 87-97.

Baigent, C. (2005). Cholesterol Treatment Trialists' (CTT) Collaborators. Efficacy and safety of cholesterol-lowering treatment: prospective meta-analysis of data from 90,056 participants in 14 randomised trials of statins. Lancet 366: 1267-1278.

Berrougui, H., Grenier, G., Loued, S., Drouin, G., and Khalil, A. (2009). A new insight into resveratrol as an atheroprotective compound: inhibition of lipid peroxidation and enhancement of cholesterol efflux. Atherosclerosis 207(2): 420-427.

Brown, L., Rosner, B., Willett, W.W., and Sacks, F.M. (1999). Cholesterollowering effects of dietary fiber: a meta-analysis. Am. J Clin. Nutr. 69(1): 30-42

Burke, F.M. (2015). Red yeast rice for the treatment of dyslipidemia. Curr. Atheroscler. Rep. 17(4): 22-26.

Cai, H., and Harrison, D.G. (2000). Endothelial dysfunction in cardiovascular diseases: the role of oxidant stress. Circ. Res. 87(10): 840-844.

Cardillo, C., Kilcoyne, C.M., Cannon, R.O., Quyyumi, A.A., and Panza, J.A (1997). Xanthine oxidase inhibition with oxypurinol improves endothelial vasodilator function in hypercholesterolemic but not in hypertensive patients. Hypertension 30(1): 57-63.

Carnethon, M.R., Gulati, M., and Greenland, P. (2005). Prevalence and cardiovascular disease correlates of low cardiorespiratory fitness in adolescents and adults. JAMA 294(23): 2981-2988.

Catapano, A.L., Reiner, Z., and De Backer, G. (2011). European Atherosclerosis Society (EAS). ESC/EAS Guidelines for the management of dyslipidaemias The Task Force for the management of dyslipidaemias of the European Society of Cardiology (ESC) and the European Atherosclerosis Society (EAS. Atherosclerosis 217(1): 3-46.

Charradi, K., Mahmoudi, M., Elkahoui, S., Limam, F., and Aouani, E. (2013). Grape seed and skin extract mitigates heart and liver oxidative damage induced by a high-fat diet in the rat: gender dependency. Can 
Physiol. Pharmacol. 91(12): 1076-1085.

Chaudhary, R., Garg, J., Shah, N., and Sumner, A. (2017). PCSK9 inhibitors: A new era of lipid lowering therapy. World J Cardiol. 9(2): 76-81.

Chen, G., Wang, H., Zhang, X., and Yang, S.T. (2014). Nutraceuticals and functional foods in the management of hyperlipidemia. Crit. Rev. Food Sci. Nutr. 54(9): 1180-1201.

Chen, Z.Y., Jiao, R., and Ma, K.Y. (2008). Cholesterol-lowering nutraceuticals and functional foods. J Agric. Food Chem. 56(19): 8761-8773.

Chiu, H.F., Chen, B.K., Lu, Y.Y., Han, Y.C., Shen, Y.C., Venkatakrishnan, K., Golovinskaia, O., and Wang, C.K. (2017). Hypocholesterolemic efficacy of royal jelly in healthy mild hypercholesterolemic adults. Pharm. Biol. 55(1): 497-502.

Chiu, H.F., Chen, Y.J., Lu, Y.Y., Han, Y.C., Shen, Y.C., Venkatakrishnan, K., and Wang, C.K. (2017). Regulatory efficacy of fermented plant extract on the intestinal microflora and lipid profile in mildly hypercholesterolemic individuals. J Food Drug Anal. 25(4): 819-827.

Chiu, H.F., Huang, Y.C., Lu, Y.Y., Han, Y.C., Shen, Y.C., Golovinskaia, O., Venkatakrishnan, K., and Wang, C.K. (2017). Regulatory/modulatory effect of prune essence concentrate on intestinal function and blood lipids. Pharm. Biol. 55(1): 974-979.

Chiu, H.F., Lin, T.Y., Shen, Y.C., Venkatakrishnan, K., and Wang, C.K. (2016). Improvement of green tea polyphenol with milk on skin with respect to antioxidation in healthy adults: a double-blind placebo-controlled randomized crossover clinical trial. Food Funct. 7(2): 893-901.

Chiu, H.F., Shen, Y.C., Huang, T.Y., Venkatakrishnan, K., and Wang, C.K. (2016). Cardioprotective efficacy of red wine extract of onion in healthy hypercholesterolemic subjects. Phytother. Res. 30(3): 380385.

Cho, S.J., Juillerat, M.A., and Lee, C.H. (2007). Cholesterol lowering mechanism of soybean protein hydrolysate. J Agric. Food Chem. 55(26): 10599-10604.

Chtourou, Y., Slima, A.B., Makni, M., Gdoura, R., and Fetoui, H. (2015). Naringenin protects cardiac hypercholesterolemia-induced oxidative stress and subsequent necroptosis in rats. Pharmacol. Rep. 67(6): 1090-1097.

Chung, V.C., Liu, S., and Sit, R.W. (2014). Medical Synopsis: Is red yeast rice capsule beneficial for treating dyslipidemia amongst statin-intolerant patients as compared to placebo? Adv. Integr. Med. 1(3): 151-152.

Cicero, A.F., Fogacci, F., and Colletti, A. (2017). Potential role of bioactive peptides in prevention and treatment of chronic diseases: a narrative review. Br J Pharmacol 174(11): 1378-1394.

Csont, T., Bereczki, E., Bencsik, P., Fodor, G., Görbe, A., Zvara, Á., Csonka, C., Puskás, L.G., Sántha, M., and Ferdinandy, P. (2007). Hypercholesterolemia increases myocardial oxidative and nitrosative stress thereby leading to cardiac dysfunction in apoB-100 transgenic mice. Cardiovasc. Res. 76(1): 100-109.

Davidson, M.H., Armani, A., McKenney, J.M., and Jacobson, T.A. (2007). Safety considerations with fibrate therapy. Am J Cardiol. 99(6): S3S18.

Deepa, P.R., and Varalakshmi, P. (2005). Atheroprotective effect of exogenous heparin-derivative treatment on the aortic disturbances and lipoprotein oxidation in hypercholesterolemic diet fed rats. Clin. Chim. Acta. 355(1): 119-130.

Deepa, P.R., and Varalakshmi, P. (2003). Salubrious effect of low molecular weight heparin on atherogenic diet-induced cardiac, hepatic and renal lipid peroxidation and collapse of antioxidant defences. Mol. Cell. Biochem. 254(1): 111-116.

Deji, N., Kume, S., Araki, S.I., Soumura, M., Sugimoto, T., Isshiki, K., and Kashiwagi, A. (2009). Structural and functional changes in the kidneys of high-fat diet-induced obese mice. Am J Physiol Renal Physiol. 296(1): F118-F126.

Demonty, I., Ras, R.T., van der Knaap, H.C., Duchateau, G.S., Meijer, L., Zock, P.L., Geleijnse, J.M., and Trautwein, E.A. (2008). Continuous dose-response relationship of the LDL-cholesterol-lowering effect of phytosterol intake. J Nutr. 139(2): 271-84.

Deng, R., and Chow, T.J. (2010). Hypolipidemic, antioxidant, and antiinflammatory activities of microalgae Spirulina. Cardiovasc Ther. 28(4): e33-45.

Derosa, G., Maffioli, P., and Cicero, A.F. (2012). Berberine on metabolic and cardiovascular risk factors: an analysis from preclinical evidences to clinical trials. Expert Opin. Biol. Ther. 12(8): 1113-1124.
Dilaveris, P., Giannopoulos, G., Riga, M., Synetos, A., and Stefanadis, C. (2007). Beneficial effects of statins on endothelial dysfunction and vascular stiffness. Curr Vasc. Pharmacol. 5(3): 227-237.

Dominguez, L.J., Galioto, A., Ferlisi, A., and Pineo, A. (2006). Ageing, lifestyle modifications, and cardiovascular disease in developing countries. J Nutr. Health Aging. 10(2): 143.

Dong, H., Zhao, Y., Zhao, L., and Lu, F. (2013). The effects of berberine on blood lipids: a systemic review and meta-analysis of randomized controlled trials. Planta Medica. 79(06): 437-446.

Enas, E.A., Singh, V., Munjal, Y.P., Bhandari, S., Yadave, R.D., and Manchanda, S.C. (2008). Reducing the burden of coronary artery disease in India: challenges and opportunities. Indian Heart J. 60(2): 161-175.

Erkkilä, A.T., and Lichtenstein, A.H. (2006). Fiber and cardiovascular disease risk: how strong is the evidence? J Cardiovasc. Nurs. 21(1): 3-8.

Eslick, G.D., Howe, P.R., Smith, C., Priest, R., and Bensoussan, A. (2009). Benefits of fish oil supplementation in hyperlipidemia: a systematic review and meta-analysis. Int. J Cardiol. 136(1): 4-16.

Expert Panel on Detection, E. (2001). Executive summary of the Third Report of the National Cholesterol Education Program (NCEP) expert panel on detection, evaluation, and treatment of high blood cholesterol in adults (Adult Treatment Panel III). JAMA 285(19): 2486-90.

Ferroni, P., Basili, S., Falco, A., and Davì, G. (2004). Oxidant stress and platelet activation in hypercholesterolemia. Antioxid. Redox Signal. 6(4): 747-756.

Fogari, R., and Zoppi, A. (2004). Effect of antihypertensive agents on quality of life in the elderly. Drugs Aging. 21(6): 377-393.

Fuentes, M.C., Lajo, T., Carrión, J.M., and Cuné, J. (2013). Cholesterol-lowering efficacy of Lactobacillus plantarum CECT 7527, 7528 and 7529 in hypercholesterolaemic adults. Br. J Nutr. 109(10): 1866-1872.

Gaur, S., and Agnihotri, R. (2014). Green tea: A novel functional food for the oral health of older adults. Geriatr. Gerontol. Int. 14(2): 238-250.

Gerards, M.C., Terlou, R.J., Yu, H., Koks, C.H.W., and Gerdes, V.E.A. (2015). Traditional Chinese lipid-lowering agent red yeast rice results in significant LDL reduction but safety is uncertain-a systematic review and meta-analysis. Atherosclerosis 240(2): 415-423.

Glässer, G., Graefe, E.U., Struck, F., Veit, M., and Gebhardt, R. (2002). Comparison of antioxidative capacities and inhibitory effects on cholesterol biosynthesis of quercetin and potential metabolites. Phytomed. 9(1): 33-40.

Gnoni, G.V., Paglialonga, G., and Siculella, L. (2009). Quercetin inhibits fatty acid and triacylglycerol synthesis in rat-liver cells. Eur J Clin Invest. 39(9): 761-768.

Gordon, R.Y., Cooperman, T., Obermeyer, W., and Becker, D.J. (2010). Marked variability of monacolin levels in commercial red yeast rice products: buyer beware!. Arch. Intern. Med. 170(19): 1722-1727.

Gulati, M., Pandey, D.K., Arnsdorf, M.F., Lauderdale, D.S., Thisted, R.A Wicklund, R.H., and Black, H.R. (2003). Exercise capacity and the risk of death in women. Circulation. 108(13): 1554-1559.

Guo, Z., Liu, X.M., Zhang, Q.X., Shen, Z., Tian, F.W., Zhang, H., Sun, Z.H., Zhang, H.P., and Chen, W. (2011). Influence of consumption of probiotics on the plasma lipid profile: a meta-analysis of randomised controlled trials. Nutr. Metab. Cardiovasc. Dis. 21(11): 844-850.

Gupta, S., Kapur, S., and Verma, A. (2015). Garlic: An Effective Functional Food to Combat the Growing Antimicrobial Resistance. Pertanika J Trop. Agric. Sci. 38(2): 271-78.

Gupta, S., Singh, N., and Jaggi, A.S. (2014). Alkaloids as aldose reductase inhibitors, with special reference to berberine. J Altern. Complement. Med. 20(3): 195-205.

Guyton, J.R., and Bays, H.E. (2007). Safety considerations with niacin therapy. Am. J Cardiol. 99(6): S22-S31.

Guyton, J.R. (2010). Combination regimens with statin, niacin, and intestinally active LDL-lowering drugs: alternatives to high-dose statin therapy? Curr. Opin. Lipidol. 21(4): 372-377.

Gylling, H., Plat, J., Turley, S., Ginsberg, H.N., Ellegård, L., Jessup, W., Jones, P.J., Lütjohann, D., Maerz, W., Masana, L., and Silbernagel, G. (2014). Plant sterols and plant stanols in the management of dyslipidaemia and prevention of cardiovascular disease. Atherosclerosis. 232(2): 346-360.

Musa-Veloso, K., Poon, T.H., Elliot, J.A., and Chung, C. (2011). A comparison of the LDL-cholesterol lowering efficacy of plant stanols and plant sterols over a continuous dose range: results of a meta-analysis 
of randomized, placebo-controlled trials. Prostaglandins. Leukot. Essent. Fatty Acids. 85(1): 9-28.

Høie, L.H., Morgenstern, E.C., Gruenwald, J., Graubaum, H.J., Busch, R., Lüder, W., and Zunft, H.J. (2005). A double-blind placebo-controlled clinical trial compares the cholesterollowering effects of two different soy protein preparations in hypercholesterolemic subjects. Eur. $J$ Nutr. 44(2): 65-71.

Hooper, L., Thompson, R.L., Harrison, R.A., Summerbell, C.D., Ness, A.R., Moore, H.J., and Riemersma, R.A. (2006). Risks and benefits of omega 3 fats for mortality, cardiovascular disease, and cancer: systematic review. BMJ 332(7544): 752-760.

Hulsmans, M., and Holvoet, P. (2010). The vicious circle between oxidative stress and inflammation in atherosclerosis. J Cell. Mol. Med. 14(1-2) 70-78

Igwe, E.O., and Charlton, K.E. (2016). A systematic review on the health effects of plums (Prunus domestica and Prunus salicina). Phytother Res. 30(5): 701-731.

Isidorov, V.A., Czyżewska, U., Isidorova, A.G., and Bakier, S. (2009). Gas chromatographic and mass spectrometric characterization of the organic acids extracted from some preparations containing lyophilized royal jelly. J Chromatogr. B. 877(29): 3776-3780.

Jiang, P., Dai, W., Yan, S., Chen, Z., Xu, R., Ding, J., and Zhang, W. (2011). Potential biomarkers in the urine of myocardial infarction rats: a metabolomic method and its application. Mol. BioSystems. 7(3): 824-831.

Jones, M.L., Martoni, C.J., Parent, M., and Prakash, S. (2012). Cholesterollowering efficacy of a microencapsulated bile salt hydrolase-active Lactobacillus reuteri NCIMB 30242 yoghurt formulation in hypercholesterolaemic adults. Br. J Nutr. 107(10): 1505-1513.

Jung, E.S., Park, S.H., Choi, E.K., Ryu, B.H., Park, B.H., Kim, D.S., and Chae, S.W. (2014). Reduction of blood lipid parameters by a 12-wk supplementation of aged black garlic: A randomized controlled trial. Nutr. 30(9): 1034-1039

Kamesh, V., and Sumathi, T. (2012). Antihypercholesterolemic effect of Bacopa monniera linn. On high cholesterol diet induced hypercholesterolemia in rats. Asian Pac. J Trop, Med. 5(12): 949-955.

Kamesh, V., and Sumathi, T. (2014). Nephroprotective potential of Bacopa monniera on hypercholesterolemia induced nephropathy via the NO signaling pathway. Pharm. Biol. 52(10): 1327-1334.

Kamesh, V, and Sumathi, T (2012). Effect of bacopa monniera linn. In attenuating hepatic oxidative stress in hypercholesterolemic induced rats. Asian J Pharm Clin Res. 5(3): 90-95.

Kashima, Y., Kanematsu, S., Asai, S., Kusada, M., Watanabe, S., Kawashima, T., Nakamura, T., Shimada, M., Goto, T., and Nagaoka, S. (2014). Identification of a novel hypocholesterolemic protein, major royal jelly protein 1, derived from royal jelly. PloS One 9(8): e105073.

Katsiki, N., Athyros, V.G., Mikhailidis, D.P., and Mantzoros, C. (2017). Proprotein convertase subtilisin-kexin type 9 (PCSK9) inhibitors: Shaping the future after the further cardiovascular outcomes research with PCSK9 inhibition in subjects with elevated risk (FOURIER) trial. Metab. Clin Exp. 74: 43-46.

Khatua, T.N., Adela, R., and Banerjee, S.K. (2013). Garlic and cardioprotection: insights into the molecular mechanisms. Can. J Physiol. Pharmacol. 91(6): 448-458.

Kim, A., Chiu, A., Barone, M.K., Avino, D., Wang, F., Coleman, C.I., and Phung, O.J. (2011). Green tea catechins decrease total and low-density lipoprotein cholesterol: a systematic review and meta-analysis. J Am. Diet. Assoc. 111(11): 1720-1729.

Kim, W.Y., and Kim, M.H. (2005). The change of lipid metabolism and immune function caused by antioxidant material in the hypercholesterolemic elderly women in Korea. Korean J Nutr. 38(1): 67-75.

Klingberg, S., Ellegård, L., Johansson, I., Hallmans, G., Weinehall, L., Andersson, H., and Winkvist, A. (2008). Inverse relation between dietary intake of naturally occurring plant sterols and serum cholestero in northern Sweden. Am. J Clin. Nutr. 87(4): 993-1001.

Kong, W., Wei, J., Abidi, P., Lin, M., Inaba, S., Li, C., and Wang, S. (2004). Berberine is a novel cholesterol-lowering drug working through a unique mechanism distinct from statins. Nat. Med. 10(12): 1344-1351.

Koo, S.I., and Noh, S.K. (2007). Green tea as inhibitor of the intestinal absorption of lipids: potential mechanism for its lipid-lowering effect. J Nutr. Biochem. 18(3): 179-183.

Kumar, P., Malhotra, P., Ma, K., Singla, A., Hedroug, O., Saksena, S., and
Alrefai, W.A. (2011). SREBP2 mediates the modulation of intestinal NPC1L1 expression by curcumin. Am J Physiol. Gastrointest. Liver Physiol. 301(1): G148-G155.

Kunsch, C., and Medford, R.M. (1999). Oxidative stress as a regulator of gene expression in the vasculature. Circ. Res. 85(8): 753-766.

Kwak, J.S., Kim, J.Y., Paek, J.E., Lee, Y.J., Kim, H.R., Park, D.S., and Kwon, O. (2014). Garlic powder intake and cardiovascular risk factors: a metaanalysis of randomized controlled clinical trials. Nutr. Res Pract. 8(6) 644-654.

Lahera, V., Goicoechea, M., Garcia de Vinuesa, S., Miana, M., Heras, N.D.L., Cachofeiro, V., and Luno, J. (2007). Endothelial dysfunction, oxidative stress and inflammation in atherosclerosis: beneficial effects of statins. Curr. Med. Chem. 14(2): 243-248.

Lee, K.H., Park, E., Lee, H.J., Kim, M.O., Cha, Y.J., Kim, J.M., and and Shin, M.J. (2011). Effects of daily quercetin-rich supplementation on cardiometabolic risks in male smokers. Nutr. Res. Pract. 5(1): 28-33.

Lee, S., Lim, H.J., Park, J.H., Lee, K.S., Jang, Y., and Park, H.Y. (2007). Ber berine-induced LDLR up-regulation involves JNK pathway. Biochem. Biophys. Res. Commun. 362(4): 853-857.

Li, H., Dong, B., Park, S.W., Lee, H.S., Chen, W., and Liu, J. (2009). Hepato cyte nuclear factor $1 \alpha$ plays a critical role in PCSK9 gene transcription and regulation by the natural hypocholesterolemic compound berberine. J Biol. Chem. 284(42): 28885-28895.

Li, X.Y., Zhao, Z.X., Huang, M., Feng, R., He, C.Y., Ma, C., and Shou, J.W. (2015). Effect of Berberine on promoting the excretion of cholesterol in high-fat diet-induced hyperlipidemic hamsters. J Transl. Med. 13(1): 278-83.

Libby, P., Ridker, P.M., Hansson, G.K., and on Atherothrombosis, L.T.N. (2009). Inflammation in atherosclerosis: from pathophysiology to practice. J Am. Coll. Cardiol. 54(23): 2129-2138.

Lu, T.M., Chiu, H.F., Shen, Y.C., Chung, C.C., Venkatakrishnan, K., and Wang, C.K. (2015). Hypocholesterolemic efficacy of quercetin rich onion juice in healthy mild hypercholesterolemic adults: a pilot study. Plant Foods Human Nutr. 70(4): 395-400.

Ma, J., Li, Y., Ye, Q., Li, J., Hua, Y., Ju, D., and and Chang, M. (2000). Constituents of red yeast rice, a traditional Chinese food and medicine. Agric. Food Chem. 48(11): 5220-5225.

Mackay, J., Mensah, G.A., and Greenlund, K. (2004). The atlas of heart disease and stroke. World Health Organization (WHO).

Mahmood, S.S., Levy, D., Vasan, R.S., and Wang, T.J. (2014). The Framingham Heart Study and the epidemiology of cardiovascular disease: a historical perspective. The Lancet. 383(9921): 999-1008.

Mann, J. (2007). Dietary carbohydrate: relationship to cardiovascular disease and disorders of carbohydrate metabolism. Eur. J Clin. Nutr. 61: S100-S111.

Mannarino, E., Pirro, M., Cortese, C., Lupattelli, G., Siepi, D., Mezzetti, A. and and Averna, M. (2009). Effects of a phytosterol-enriched dairy product on lipids, sterols and 8-isoprostane in hypercholesterolemic patients: a multicenter Italian study. Nutr. Metab. Cardiovasc. Dis. 19(2): 84-90.

Mannarino, M.R., Ministrini, S., and Pirro, M. (2014). Nutraceuticals for the treatment of hypercholesterolemia. Eur. J Intern. Med. 25(7) 592-599.

Marazzi, G., Cacciotti, L., Pelliccia, F., laia, L., Volterrani, M., Caminiti, G. Sposato, B., Massaro, R., Grieco, F., and Rosano, G. (2011). Long-term effects of nutraceuticals (berberine, red yeast rice, policosanol) in elderly hypercholesterolemic patients. Adv. Ther. 28(12): 1105-1113.

Maron, D.J., Lu, G.P., Cai, N.S., Wu, Z.G., Li, Y.H., Chen, H., Zhu, J.Q., Jin, X.J., Wouters, B.C., and Zhao, J. (2003). Cholesterol-lowering effect of a theaflavin-enriched green tea extract: a randomized controlled trial. Arch Intern. Med. 163(12): 1448-1453.

Mathew, B.C., Prasad, N.V., and Prabodh, R. (2004). Cholesterol-lowering effect of organosulphur compounds from garlic: a possible mechanism of action. Kathmandu Univ Med J. 2(2): 100-02.

Mazokopakis, E.E., Starakis, I.K., Papadomanolaki, M.G., Mavroeidi, N.G. and Ganotakis, E.S. (2014). The hypolipidaemic effects of Spirulina (Arthrospira platensis) supplementation in a Cretan population: prospective study. J Sci. Food Agric. 94(3): 432-437.

Nagaoka, S., Nakamura, A., Shibata, H., and Kanamaru, Y. (2010). Soystatin (VAWWMY), a novel bile acid-binding peptide, decreased micellar solubility and inhibited cholesterol absorption in rats. Biosci. Bio- 
technol. Biochem. 74(8): 1738-1741.

Nagaoka, S., Shimizu, K., Kaneko, H., Shibayama, F., Morikawa, K., Kanamaru, Y., Otsuka, A., Hirahashi, T., and Kato, T. (2005). A novel protein C-phycocyanin plays a crucial role in the hypocholesterolemic action of Spirulina platensis concentrate in rats. J Nutr. 135(10): 2425-2430.

Nelson, R.H. (2013). Hyperlipidemia as a risk factor for cardiovascular disease. Prim Care: Clin Office Pract. 40(1): 195-211.

Nguyen, T.T., Dale, L.C., Von Bergmann, K., and Croghan, I.T. (1999). Cholesterol-lowering effect of stanol ester in a US population of mildly hypercholesterolemic men and women: a randomized controlled trial. In Mayo Clinic Proceedings 74(12): 1198-1206.

Nies, L.K., Cymbala, A.A., Kasten, S.L., Lamprecht, D.G., and Olson, K.L. (2006). Complementary and alternative therapies for the management of dyslipidemia. Ann. Pharmacother. 40(11): 1984-1992.

Nordestgaard, B.G., Chapman, M.J., Ray, K., Borén, J., Andreotti, F., Watts, G.F., and Fisher, E. (2010). Lipoprotein (a) as a cardiovascular risk factor: current status. Eur Heart J. 31(23): 2844-2853.

Out, C., Groen, A.K., and Brufau, G. (2012). Bile acid sequestrants: more than simple resins. Curr. Opin. Lipidol. 23(1): 43-55.

Pagidipati, N.J., and Gaziano, T.A. (2013). Estimating deaths from cardiovascular disease: a review of global methodologies of mortality measurement. Circulation. 127(6): 749-756.

Pahan, K. (2006). Lipid-lowering drugs. Cell. Mol. Life Sci. CMLS 63(10): 1165-1178.

Panahi, Y., Kianpour, P., Mohtashami, R., Jafari, R., Simental-Mendía, L.E., and Sahebkar, A. (2016). Curcumin lowers serum lipids and uric acid in subjects with nonalcoholic fatty liver disease: a randomized controlled trial. J Cardiovasc. Pharmacol. 68(3): 223-229.

Pasternak, R.C. (2002). 2001 National Cholesterol Education Program (NCEP) Guidelines on the Detection, Evaluation and Treatment of Elevated Cholesterol in Adults: Adult Treatment Panel III (ATP III). ACC Curr. J Rev. 11(4): 37-45.

Phan, B.A.P., Dayspring, T.D., and Toth, P.P. (2012). Ezetimibe therapy: mechanism of action and clinical update. Vasc. Health Risk Manag. 8: 415-19.

Pickle, L.W., and Gillum, R.F. (1999). Geographic variation in cardiovascular disease mortality in US blacks and whites. J Natl. Med. Assoc. 91(10): 545-51.

Pisciotta, L., Bellocchio, A., and Bertolini, S. (2012). Nutraceutical pill containing berberine versus ezetimibe on plasma lipid pattern in hypercholesterolemic subjects and its additive effect in patients with familial hypercholesterolemia on stable cholesterol-lowering treatment. Lipids Health Dis. 11(1): 123.

Ramadan, M.F., and Al-Ghamdi, A. Bioactive compounds and health-promoting properties of royal jelly. Rev. J. Funct. Foods 4(1): 39-52.

Ramamoorthy, A., and Premakumari, S. (1996). Effect of supplementation of Spirulina on hypercholesterolemic patients. J Food Sci Technol. 33(2): 124-128.

Ras, R.T., Geleijnse, J.M., and Trautwein, E.A. (2014). LDL-cholesterol-lowering effect of plant sterols and stanols across different dose ranges: a meta-analysis of randomised controlled studies. Br. J Nutr. 112(2): 214-219.

Razavi, S.M., Gholamin, S., Eskandari, A., Mohsenian, N., Ghorbanihaghjo, A., Delazar, A., and Argani, H. (2013). Red grape seed extract improves lipid profiles and decreases oxidized low-density lipoprotein in patients with mild hyperlipidemia. J Med Food. 16(3): 255-258.

Rebholz, C.M., Reynolds, K., Wofford, M.R., Chen, J., Kelly, T.N., Mei, H., Whelton, P.K., and He, J. (2013). Effect of soybean protein on novel cardiovascular disease risk factors: a randomized controlled trial. Eur. J Clin. Nutr. 67(1): 58-63.

Rerksuppaphol, S., and Rerksuppaphol, L. (2015). A randomized doubleblind controlled trial of lactobacillus acidophilus plus bifidobacterium bifidum versus placebo in patients with hypercholesterolemia. J. Clin. Diagn. Res. 9(3): KC01-04.

Ried, K., Toben, C., and Fakler, P. (2013). Effect of garlic on serum lipids: an updated meta-analysis. Nutr Rev. 71(5): 282-299.

Ross, R. (1999). Atherosclerosis-an inflammatory disease. New Engl. J Med. 340(2): 115-126.

Ryan, P.M., Ross, R.P., Fitzgerald, G.F., Caplice, N.M., and Stanton, C. (2015). Functional food addressing heart health: do we have to target the gut microbiota? Curr. Opin. Clin. Nutr. Metab. Care. 18(6):
$566-571$.

Sahebkar, A., Serban, M.C., Gluba-Brzózka, A., Mikhailidis, D.P., Cicero, A.F., Rysz, J., and Banach, M. (2016). Lipid-modifying effects of nutraceuticals: An evidence-based approach. Nutr. 32(11): 1179-1192.

Sandhya, V.G., and Rajamohan, T. (2008). Comparative evaluation of the hypolipidemic effects of coconut water and lovastatin in rats fed fatcholesterol enriched diet. Food Chem. Toxicol. 46(12): 3586-3592.

Serban, M.C., Sahebkar, A., Dragan, S., Stoichescu-Hogea, G., Ursoniu, S., Andrica, F., and Banach, M. (2016). A systematic review and metaanalysis of the impact of Spirulina supplementation on plasma lipid concentrations. Clin. Nutr. 35(4): 842-851.

Shahidi, F., and Ambigaipalan, P. (2018). Omega-3 polyunsaturated fatty acids and their health benefits. Annu. Rev. Food Sci. Technol. 9(1): 345-381.

Shattat, G.F. (2015). A review article on hyperlipidemia: types, treatments and new drug targets. Biomed. Pharmacol. J. 7(1): 399-409.

Shishikura, Y., Khokhar, S., and Murray, B.S. (2006). Effects of tea polyphenols on emulsification of olive oil in a small intestine model system. Journal of agric. Food Chem. 54(5): 1906-1913.

Simionescu, M. (2007). Implications of early structural-functional changes in the endothelium for vascular disease. Arterioscler. Thromb. Vasc. Biol. 27(2): 266-274.

Stacewicz-Sapuntzakis, M., Bowen, P.E., Hussain, E.A., Damayanti-Wood, B.I., and Farnsworth, N.R. (2001). Chemical composition and potential health effects of prunes: a functional food? Crit. Rev. Food Sci. Nutr. 41(4): 251-286.

Stacewicz-Sapuntzakis, M. (2013). Dried plums and their products: composition and health effects-an updated review. Crit. Rev. Food Sci. Nutr. 53(12): 1277-1302.

Steinberg, D. (2005). Thematic review series: the pathogenesis of atherosclerosis. An interpretive history of the cholesterol controversy: part II: the early evidence linking hypercholesterolemia to coronary disease in humans. J Lipid Res. 46(2): 179-190.

Steinl, D.C., and Kaufmann, B.A. (2015). Ultrasound imaging for risk assessment in atherosclerosis. Int J Mol. Sci. 16(5): 9749-9769.

Stemerman, M.B. (2000). Lipoprotein effects on the vessel wall. Circ. Res. 86: 715-716.

Stocker, R., and Keaney, J.F. (2004). Role of oxidative modifications in atherosclerosis. Physiol. Rev. 84(4): 1381-1478.

Stokes, K.Y., Clanton, E.C., Gehrig, J.L., and Granger, D.N. (2003). Role of interleukin 12 in hypercholesterolemia-induced inflammation. Am. J. Physiol. Heart Circ. Physiol. 285(6): H2623-H2629.

Stokes, K.Y., Dugas, T.R., Tang, Y., Garg, H., Guidry, E., and Bryan, N.S (2009). Dietary nitrite prevents hypercholesterolemic microvascular inflammation and reverses endothelial dysfunction. Am. J. Physiol. Heart Circ. Physiol. 296(5): H1281-H1288.

Stokes, K.Y. (2006). Microvascular responses to hypercholesterolemia: the interactions between innate and adaptive immune responses. Antioxid. Redox signal. 8(7-8): 1141-1151.

Sudhahar, V., Kumar, S.A., Sudharsan, P.T., and Varalakshmi, P. (2007). Protective effect of lupeol and its ester on cardiac abnormalities in experimental hypercholesterolemia. Vasc. Pharmacol. 46(6): 412-418.

Tai, M.H., Chen, P.K., Chen, P.Y., Wu, M.J., Ho, C.T., and Yen, J.H. (2014). Curcumin enhances cell-surface LDLR level and promotes LDL uptake through downregulation of PCSK9 gene expression in HepG2 cells. Mol. Nutr Food Res. 58(11): 2133-2145.

Thiruchenduran, M., Vijayan, N.A., Sawaminathan, J.K., and Devaraj, S.N. (2011). Protective effect of grape seed proanthocyanidins against cholesterol cholic acid diet-induced hypercholesterolemia in rats. Cardiovasc. Pathol. 20(6): 361-368.

Thushara, R.M., Gangadaran, S., Solati, Z., and Moghadasian, M.H. (2016). Cardiovascular benefits of probiotics: a review of experimental and clinical studies. Food Funct. 7(2): 632-642

Tibolla, G., Norata, G.D., Artali, R., Meneghetti, F., and Catapano, A.L. (2011). Proprotein convertase subtilisin/kexin type 9 (PCSK9): From structure-function relation to therapeutic inhibition. Nutr Metab. Cardiovasc. Dis. 21(11): 835-843.

Tokede, O.A., Onabanjo, T.A., Yansane, A., Gaziano, J.M., and Djoussé, L. (2015). Soya products and serum lipids: a meta-analysis of randomised controlled trials. Br. J Nutr. 114(6): 831-843.

Ueshima, H., Sekikawa, A., Miura, K., Turin, T.C., Takashima, N., Kita, Y., 
Watanabe, M., Kadota, A., Okuda, N., Kadowaki, T., and Nakamura, Y. (2008). Cardiovascular disease and risk factors in Asia. Circulation. 118(25): 2702-2709.

Utermann, G. (2001). Lipoprotein (a). The metabolic and molecular bases of inherited disease. 8th ed. New York: McGraw-Hill, pp. 2753-2787.

Van Rooy, M.J., and Pretorius, E. (2014). Obesity, hypertension and hypercholesterolemia as risk factors for atherosclerosis leading to ischemic events. Curr. Med. Chem. 21(19): 2121-2129.

Verhoeven, V., Hartmann, M.L., Remmen, R., Wens, J., Apers, S., and Van Royen, P. (2013). Red yeast rice lowers cholesterol in physicians-a double blind, placebo controlled randomized trial. BMC Complement Altern. Med. 13(1): 178.

Wang, F., Wang, Y., Zhu, Y., Liu, X., Xia, H., Yang, X., and Sun, G. (2017). Treatment for 6 months with fish oil-derived $n-3$ polyunsaturated fatty acids has neutral effects on glycemic control but improves dyslipidemia in type 2 diabetic patients with abdominal obesity: A randomized, double-blind, placebo-controlled trial. Eur. J Nutr. 56(7): $2415-2422$.

Weggemans, R.M., and Trautwein, E.A. (2003). Relation between soy-associated isoflavones and LDL and HDL cholesterol concentrations in humans: a meta-analysis. Eur. J Clin. Nutr. 57(8): 940-946.

Whitehead, A., Beck, E.J., Tosh, S., and Wolever, T.M. (2014). Cholesterol- lowering effects of oat $\beta$-glucan: a meta-analysis of randomized controlled trials. Am J Clin. Nutr. 100(6): 1413-1421.

Yamamoto, A. (2008). A uniqe antilipidemic drug-probucol. J Atheroscler. Thromb. 15(6): 304-305.

Yang, Y.S., Su, Y.F., Yang, H.W., Lee, Y.H., Chou, J.I., and Ueng, K.C. (2014). Lipid-Lowering Effects of Curcumin in Patients with Metabolic Syndrome: A Randomized, Double-Blind, Placebo-Controlled Trial. Phytother. Res. 28(12): 1770-1777.

Ying, Y., Xing-kui, T., Xiao-cheng, L., and Ju-fang, S. (2005). Early renal morphological changes in high-cholesterol diet rats model. Wuhan Univ $J$ Nat. Sci. 10(6): 1063-1068.

Zeng, T., Guo, F.F., Zhang, C.L., Song, F.Y., Zhao, X.L., and Xie, K.Q. (2012). A meta-analysis of randomized, double-blind, placebo-controlled trials for the effects of garlic on serum lipid profiles. J Sci Food Agric. 92(9): 1892-1902.

Zhu, W., Dong, C., Du, H., Zhang, H., Chen, J., Hu, X., and Hu, F. (2014) Effects of fish oil on serum lipid profile in dialysis patients: a systematic review and meta-analysis of randomized controlled trials. Lipids Health Dis. 13(1): 127.

Zlotogorski, A., Dayan, A., Dayan, D., Chaushu, G., Salo, T., and Vered, M. (2013). Nutraceuticals as new treatment approaches for oral cancerI: Curcumin. Oral Oncol. 49(3): 187-191. 